Sensors 2008, 8, 6791-6809; DOI: 10.3390/s8116791

ISSN 1424-8220

www.mdpi.com/journal/sensors

Article

\title{
An Electrochemical DNA Biosensor Developed on a Nanocomposite Platform of Gold and Poly(propyleneimine) Dendrimer
}

\author{
Omotayo Arotiba, Joseph Owino, Everlyne Songa, Nicolette Hendricks, Tesfaye Waryo, Nazeem \\ Jahed, Priscilla Baker and Emmanuel Iwuoha*
}

SensorLab, Department of Chemistry, University of the Western Cape, Bellville, Cape Town 7535, South Africa; E-mails: oarotiba@uwc.ac.za; jowino@uwc.ac.za; esonga@uwc.a.za; nhendricks@uwc.ac.za; twaryo@uwc.ac.za; njahed@uwc.ac.za; pbaker@uwc.ac.za

* Author to whom correspondence should be addressed; E-mail: eiwuoha@uwc.ac.za; Tel.: +27 21959 3054; Fax: +27 219591562 .

Received: 29 September 2008; in revised form: 22 October 2008 / Accepted: 27 October 2008 /

Published: 1 November 2008

\begin{abstract}
An electrochemical DNA nanobiosensor was prepared by immobilization of a 20mer thiolated probe DNA on electro-deposited generation 4 (G4) poly(propyleneimine) dendrimer (PPI) doped with gold nanoparticles (AuNP) as platform, on a glassy carbon electrode (GCE). Field emission scanning electron microscopy results confirmed the codeposition of PPI (which was linked to the carbon electrode surface by C-N covalent bonds) and AuNP ca $60 \mathrm{~nm}$. Voltammetric interrogations showed that the platform (GCE/PPI-AuNP) was conducting and exhibited reversible electrochemistry $\left(\mathrm{E}^{\circ}{ }^{\prime}=235 \mathrm{mV}\right)$ in $\mathrm{pH} 7.2$ phosphate buffer saline solution (PBS) due to the PPI component. The redox chemistry of PPI was $\mathrm{pH}$ dependent and involves a two electron, one proton process, as interpreted from a $28 \mathrm{mV} / \mathrm{pH}$ value obtained from $\mathrm{pH}$ studies. The charge transfer resistance $\left(\mathrm{R}_{\mathrm{ct}}\right)$ from the electrochemical impedance spectroscopy (EIS) profiles of GCE/PPI-AuNP monitored with ferro/ferricyanide $\left(\mathrm{Fe}(\mathrm{CN})_{6}{ }^{3-/ 4-}\right)$ redox probe, decreased by $81 \%$ compared to bare GCE. The conductivity (in PBS) and reduced $\mathrm{R}_{\mathrm{ct}}$ (in $\mathrm{Fe}(\mathrm{CN})_{6}{ }^{3-/ 4-}$ ) values confirmed PPI-AuNP as a suitable electron transfer mediator platform for voltammetric and impedimetric DNA biosensor. The DNA
\end{abstract}


probe was effectively wired onto the GCE/PPI-AuNP via Au-S linkage and electrostatic interactions. The nanobiosensor responses to target DNA which gave a dynamic linear range of 0.01 - $5 \mathrm{nM}$ in PBS was based on the changes in $\mathrm{R}_{\mathrm{ct}}$ values using $\mathrm{Fe}(\mathrm{CN})_{6}^{3-/ 4-}$ redox probe.

Keywords: Poly(propyleneimine) dendrimer, gold nanoparticle, electrochemical impedance spectroscopy, electrochemical DNA biosensor, DNA.

\section{Introduction}

A biosensor is an analytical device that incorporates a bioreceptor onto a transducer surface and in the presence of an analyte, produces measurable signals (due to a bio-recognition event) that are proportional to the analyte concentration. Biosensors can be classified using either the bioreceptor or the transduction method or both. The common bioreceptors are enzyme [1-4], antibody [5, 6], DNA [7, 8] and whole cell [9], while transduction methods include electrochemical, pizoelectric, optical, etc. [5, 10]. Biosensors exploit the excellent selectivity, specificity and reactivities of immobilized biomaterials towards their substrates. They are relatively less expensive, faster, more user friendly and miniaturizable, compared to traditional instrumental methods. Owing to these unique qualities, biosensors are increasingly being applied in biomedical and environmental analysis.

Recently, Mascini and co workers [11] reported an electrochemical DNA biosensor for the detection of low-molecular-mass substances that are of environmental concern, including polychlorinated biphenyls (PCBs) and aflaxtoxins. Other researchers have reported environmental biosensor systems for the detection of organophosphates in air, soil and water [12], pesticides in soil [13], water pollutants [14, 15], food contaminants [16,17], explosives [18] and chemical warfare agents [19]. Despite the milestones achieved in biosensor development and applications, there still remains the challenge of achieving lower detection limits, greater sensitivity, biocompatibility and reproducibility [20]. The step in biosensor preparation that has the greatest impact on biosensor performance is the immobilization of the biomolecular probe. The two routes usually adopted to optimize the immobilization of biomolecules are chemical modification of the substrate and biological functionalization of the biomolecule [21], both of which determine the immobilisation chemistry. Lucarelli et al. [8] and Sassolas et al. [22] demonstrated in their studies how the functionalization of oligonucleotides improves their immobilization chemistry and hence the performance of DNA biosensors. On the other hand, the modification of electrodes or substrates using nanomaterials such as metal oxide nanoparticles [23, 24] and polymers [25] are now emerging. In this study, the functionalization of both the immobilization platform and the DNA will be performed with the aim of improving the biosensor response characteristics. This involves the use of GCE modified with dendrimeric materials that are doped with gold nanoparticles. Dendrimers are synthetic three-dimensional macromolecules with a well-defined, highly branched and globular shaped molecular structure [26]. Poly(propyleneimine) (PPI) and other dendrimers such as poly(amidoamine) (PAMAM) are widely used 
in biomedical research in the form of nanoscopic containers for genes and drugs [27-29]. Dendrimers have also been used in catalysis [30, 31] and very recently in biosensors [32, 33] and microbicides [34, 35].

Gold nanoparticles (AuNP) are known to exhibit excellent biocompatibility and high conductivity. They act as bimolecular nanoscopic wires that create large electrode surface areas that suitably orient DNA molecules for optimal immobilization, and have been used to chemisorb thiolated DNA onto electrode surface [36-42]. This paper describes the preparation and electrochemical responses of a DNA nanobiosensor consisting of AuNP-doped PPI and thiolated 20mer oligonucleotide immobilized on a GCE.

\section{Results and Discussion}

\subsection{Morphology and Voltammetric behaviour of GCE/PPI-AuNP}

Figures 1a-d show the FE-SEM images of the blank SPCE, SPCE/AuNP, SPCE/PPI and SPCE/PPIAuNP, respectively. An average size of $60 \mathrm{~nm}$ AuNP can be observed deposited on the surface of the SPCE in Figure 1b (compare with blank SPCE in Figure 1a). Figure 1c confirms the attachment of PPI onto the carbon surface, seen as a globular growth on the SPCE. At the point of measurement, Figure 1d exhibited a reflectance not observed in Figure 1c as a result of the AuNP which was co-deposited. The diameter of G4 PPI is about $3.12 \mathrm{~nm}$ [43] and has been known to be flexible thus in Figure 1d,

Figure 1. FE-SEM images on screen printed carbon electrodes (SPCE) (a) blank SPCE. (b) SPCE/AuNP. (c) SPCE/PPI (d). SPCE/PPI-AuNP.
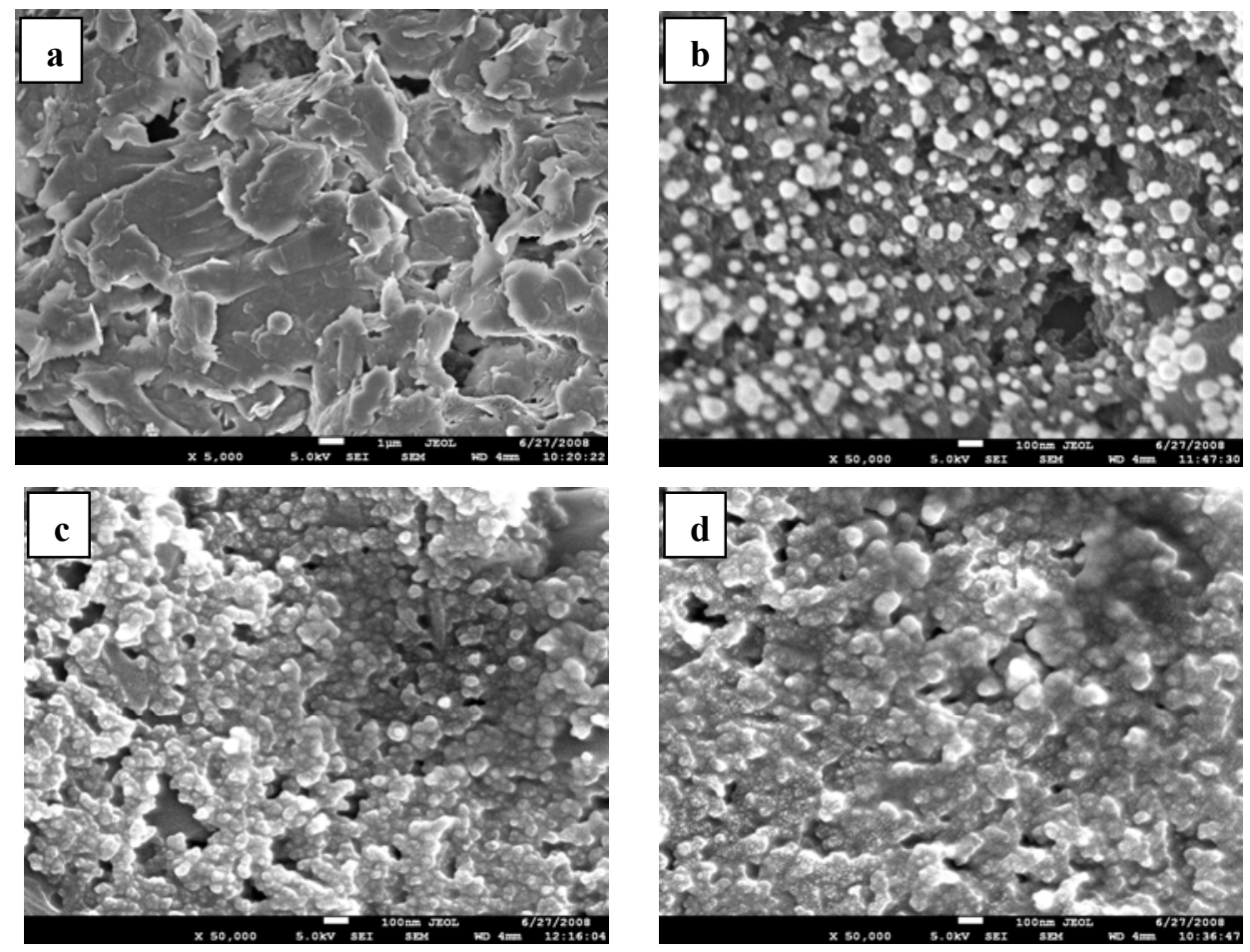
PPI appears to cluster around the AuNP because it is smaller in size. The nanocomposite however has higher particle size than the separate components; the morphology of the PPI-AuNP is similar to that of PPI only (Figure 1c). As a further proof of the presence of AuNP in Figure 1d, energy-dispersive x-ray analysis (EDAX) of the sample gave 4.95 weight percent of gold relative to carbon and other elements present. The TEM image of GCE/PPI-AuNP gave a smaller AuNP size of about $30 \mathrm{~nm}$ (result not shown) and this suggests that the roughness of the electrode (substrate) has an effect on the AuNP distribution and particle size.

The chemical (covalent) modification of GCE using either aliphatic or aromatic primary amines to form $\mathrm{C}-\mathrm{N}$ bonds has been in use for quite a while and its mechanism involves the formation of an amine cation radical [44-46]. This reaction mechanism has not been known to occur with tertiary amines [45]. G4 PPI consists of peripheral primary amines and internal tertiary amines. Thus the same chemistry should apply in the attachment of the peripheral primary amines (and not the internal tertiary amines) of PPI (Figure 2) onto the GCE (also SPCE for SEM) surface at a potential of ca $1000 \mathrm{mV}$ where electrooxidation of primary amines [45] occur. Cyclic voltammetric deposition of PPI and AuNP on the GCE, therefore, involves the formation of amine linkages between PPI and GCE while the AuNP were simultaneously deposited with the PPI.

Figure 2. Structure of G4 Poly(propylene imine) dendrimer showing the peripheral primary amine and internal tertiary amine.

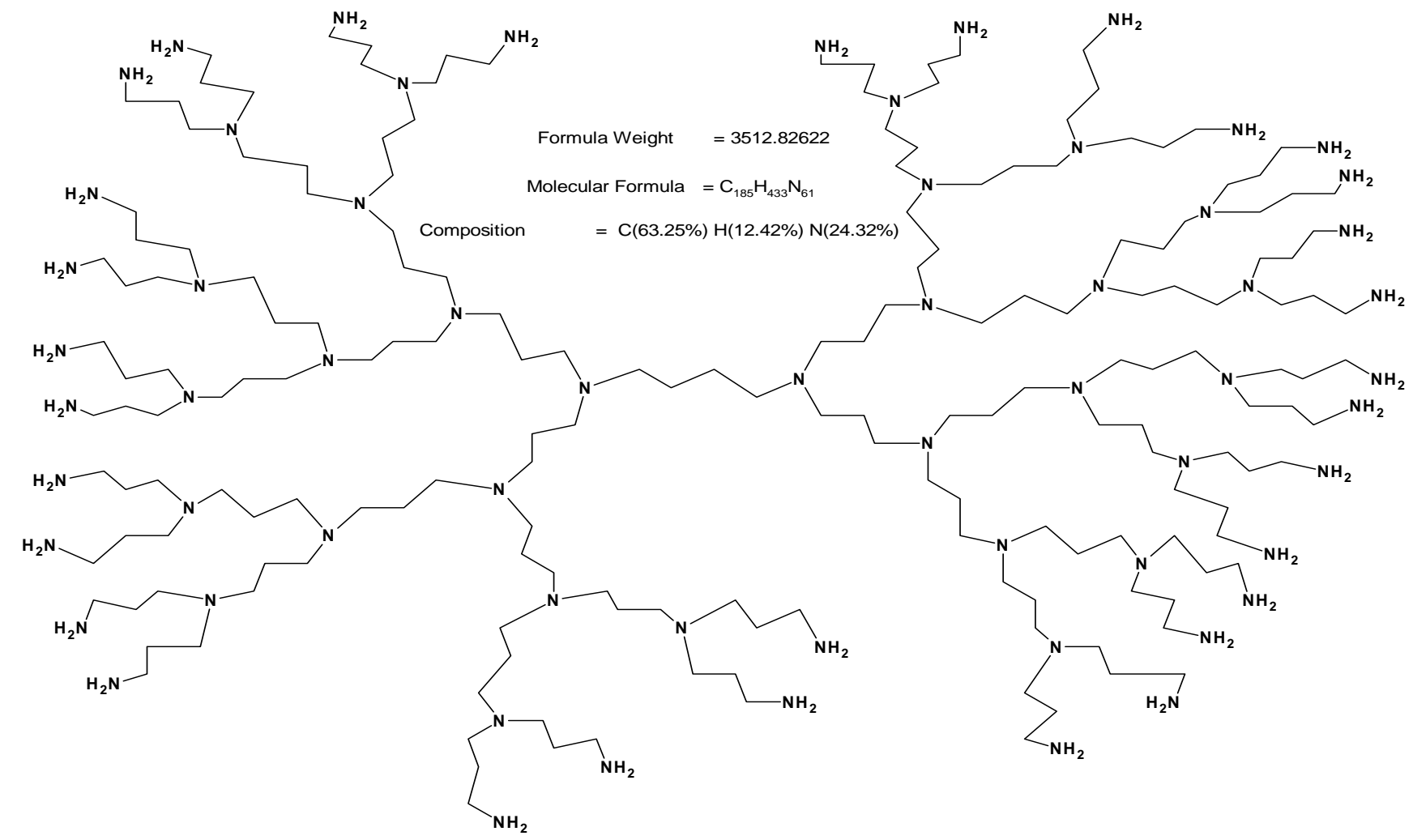


Figure 3a, compares the electrochemical behaviour of GCE/PPI-AuNP (dotted line) against the bare GCE (solid line) in PBS. The PPI-AuNP composite film exhibited reversible electrochemistry characteristic of surface adsorbed species with formal potential $\mathrm{E}^{0 \prime}=233 \pm 5 \mathrm{mV}$ for six different measurements demonstrating the good reproducibility of the composite platform. To ascertain the species responsible for the reversible peaks, PPI and AuNP were deposited alone (Figures $3 \mathrm{~b}$ and $3 \mathrm{c}$ ). In Figure 3b, $3 \mathrm{mM}$ PPI in PBS solution exhibited a quasi-reversible electrochemistry and when it was electrodeposited, the anodic and cathodic peaks separation became less. In Figure 3c, where only AuNP was deposited on GCE, no peaks were observed. This meant that the pair of peaks observed in Figure 3a (dotted line) was due to the PPI component of the nanocomposite. The reversibility of the electrochemical oxidation/reduction occurring within the PPI-AuNP nanocomposite platform was confirmed by the ratio of anodic $\left(\mathrm{I}_{\mathrm{pa}}\right)$ to cathodic $\left(\mathrm{I}_{\mathrm{pc}}\right)$ peak currents, which was calculated to give 0.992. Also the anodic and cathodic square wave voltammograms gave approximately the same peak potential value (see Figure $3 \mathrm{~d}$ ). In addition, the integration of the anodic and cathodic CV peaks from Figure 3 a (wave GCE/PPI-AuNP) gave charges of $528.1 \mathrm{nC}$ and $-524.7 \mathrm{nC}$, respectively, which are the same within experimental error.

Figure 3. (a) CV of GCE and GCE/PPI-AuNP in PBS from $-100 \mathrm{mV}$ to $650 \mathrm{mV}$ at $20 \mathrm{mV} / \mathrm{s}$. (b) CV of $3 \mathrm{mM}$ PPI solution on GCE and GCE/PPI. Background electrolyte is $10 \mathrm{mM}$ PBS. (c) $\mathrm{CV}$ of GCE and GCE/AuNP with ssDNA and dsDNA in PBS. (d) Oxidative and reductive square wave voltammograms of GCE/PPI-AuNP in PBS.
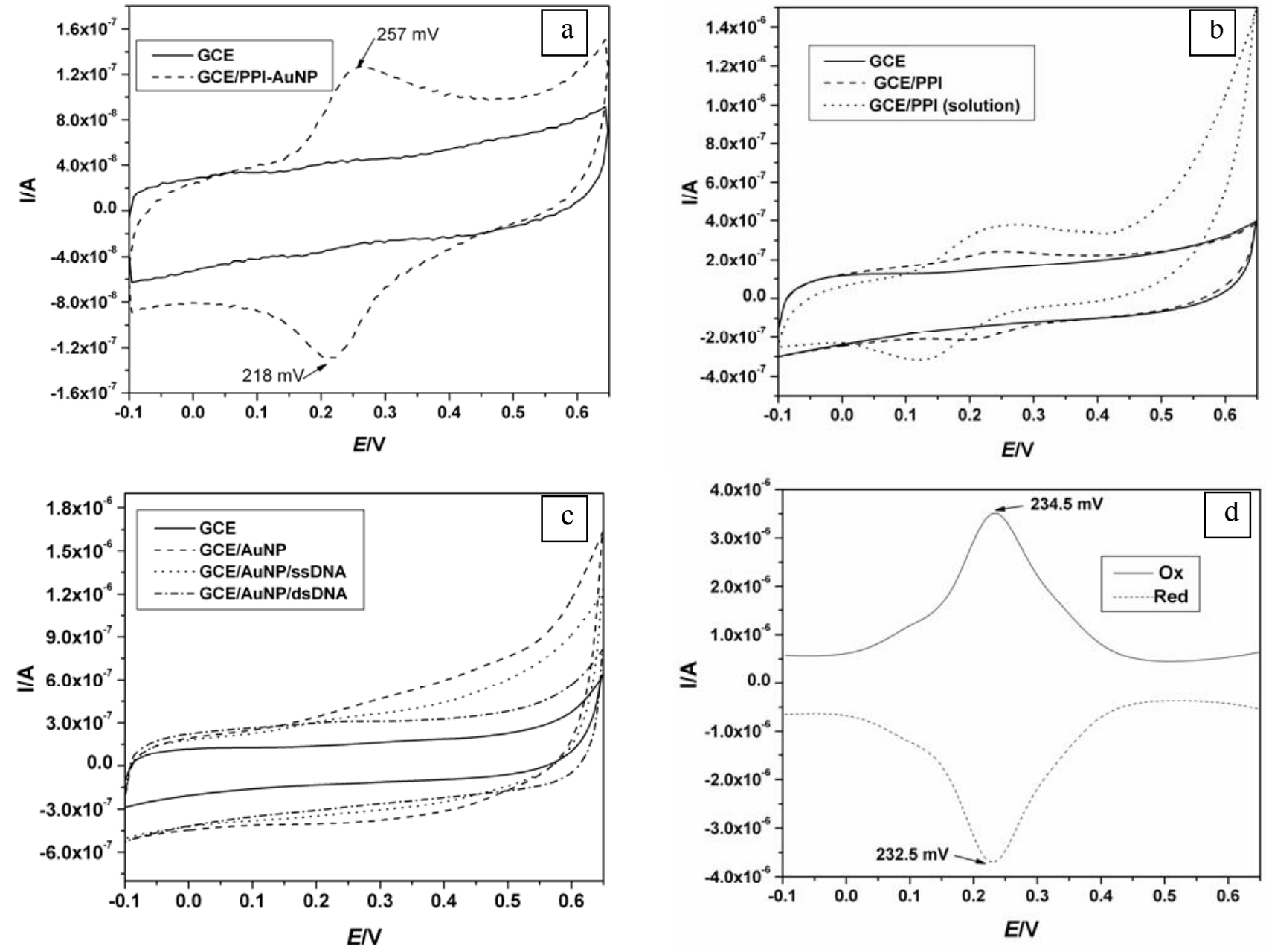
Figure 4a shows the CV of GCE/PPI-AuNP at different scan rate in PBS. From this figure, (i) the currents increased with increase in scan rate with no shift in potential, (ii) $\mathrm{I}_{\mathrm{pa}}$ was proportional to scan rate and (iii) a plot of $\mathrm{I}_{\mathrm{pa}}$ versus scan rate showed linearity (Figure 4a inset) with a correlation coefficient of 0.9978. It can thus be deduced that the platform was conducting and exhibited a reversible electrochemistry characteristic of surface adsorbed specie because $\mathrm{I}_{\mathrm{pa}}$ versus scan rate was linear. Ideally, for surface adsorbed specie, $\mathrm{E}_{\mathrm{pa}}$ should be the same as $\mathrm{E}_{\mathrm{pc}}$. However, the $\Delta \mathrm{E}$ of ca $30 \mathrm{mV}$ observed here may be as a result of diffusion of electrons along the PPI matrix and suggests a two electron system. The fact that there was no shift in potential and the $\mathrm{I}_{\mathrm{pa}} / \mathrm{I}_{\mathrm{pc}}$ remained unity also showed the stability of the PPIAuNP platform in PBS.

Figure 4. (a) $\mathrm{CV}$ of the GCE/PPI-AuNP in PBS as a function of scan rate (inset is the scan rate dependence of $\mathrm{I}_{\mathrm{pa}}$ ). (b) Plot of $\mathrm{E}_{\mathrm{pa}}$ and $\mathrm{I}_{\mathrm{pa}} \mathrm{vs} \mathrm{pH}$ and $\mathrm{SWV}$ (inset) response of platform in $0.1 \mathrm{M}$ PBS ant different $\mathrm{pH}$.
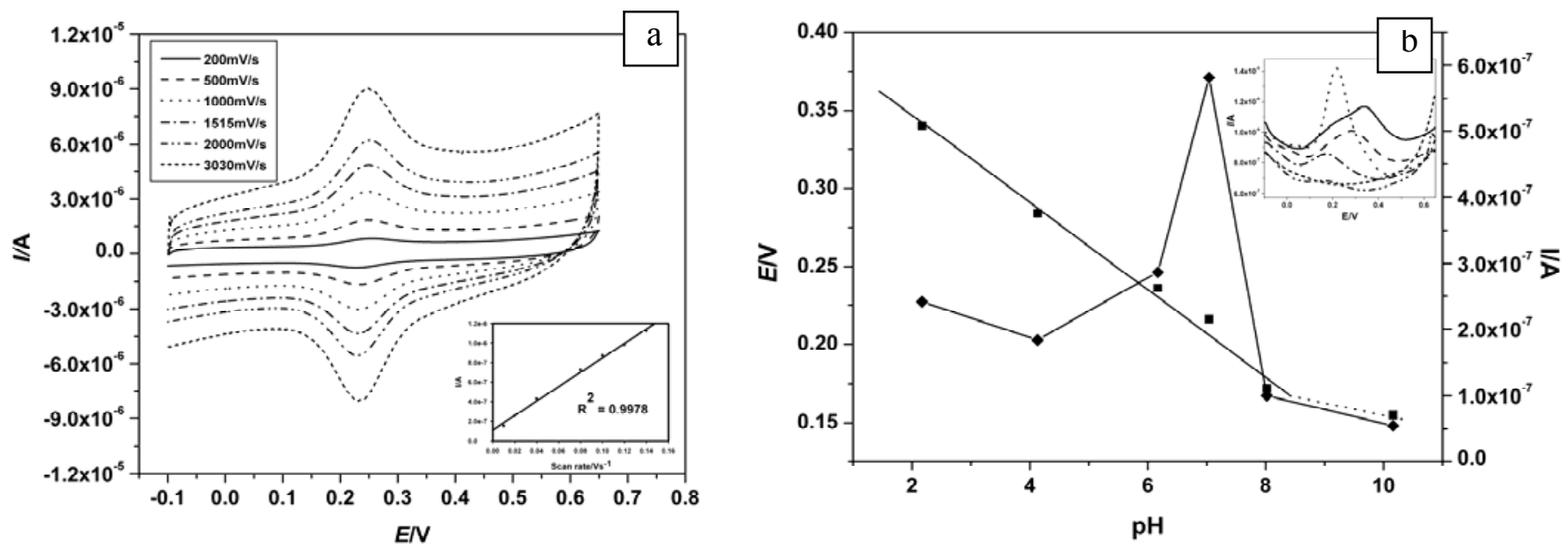

\section{$2.2 \mathrm{pH}$ studies of GCE/PPI}

The PPI on the electrode consists of secondary and tertiary amine molecules which are responsible for its reaction. PPI are positively charged (cationic) polyelectrolyte in their protonated form. The ionization behavior of PPI has been studied using potentiometry and NMR. These studies [48, 49] revealed that PPI can be protonated to a degree of $2 / 3$. For more insights into the number of electron(s) and proton(s) involved in the electrochemistry of immobilized PPI, effect of variation in $\mathrm{pH}$ on its voltammetric response was studied in PBS. From the CV (Table 1) and SWV (Table 1 and Figure 4b) data, it can be inferred that the optimum $\mathrm{pH}$ for the PPI's reversibility and conductivity is ca. 7. Figure $4 \mathrm{~b}$ shows the plot of $\mathrm{E}_{\mathrm{pa}}$ and $\mathrm{I}_{\mathrm{pa}} \mathrm{vs} \mathrm{pH}$ obtained from SWV (Figure $4 \mathrm{~b}$ inset). $\mathrm{E}_{\mathrm{pa}}$ shifted cathodically (to lower values) as $\mathrm{pH}$ increased from 2 to 8 (Figure $4 \mathrm{~b}$ solid line (-)) following the relationship $E_{p a}=399.97-0.028 p H$ (and $E^{\circ^{\prime}}=425.74-0.030 \mathrm{pH}$ for $\mathrm{CV}$ ). The $28 \mathrm{mV}$ per $\mathrm{pH}$ unit, which is close to the Nernstian value of 29.5 $\mathrm{mV}(59 / \mathrm{n}$ for $\mathrm{n}=2)$, showed that the redox mechanism of PPI involves a two electron, one proton process 
[50]. Above the $\mathrm{pH}$ of 8.5 there was a deviation from this relationship and the electrochemistry was completely quenched at $\mathrm{pH} 12$. From this response to $\mathrm{pH}$, it can be inferred that the electrochemistry of the nanocomposite is facile only when the dendrimer is moderately protonated. The $\mathrm{pKa}$ of tertiary amines is ca. $10(\mathrm{pKb}=4)$ thus, the common rules (derived from Henderson-Hasselbach equation) which states that (i), at $p H \leq p K a-2$ the substance exists mostly in its associated or protonated form and (ii), at $p H \geq p K a+2$ the substance exists mostly in its dissociated or deprotonated form, supports our observation. The dendrimer can be thought to be practically completely protonated up to the $\mathrm{pH}$ of 8.5 and below and totally deprotonated above $\mathrm{pH} 12$. The $\mathrm{pH}$ dependence of PPI observed agrees with Koper and co-workers [51], who carried out a ${ }^{15} \mathrm{~N}-\mathrm{NMR}$ study of PPI using Ising model. They observed variations in the chemical shifts of tertiary nitrogens with $\mathrm{pH}$ as a result of protonation, which vary in degree from shell to shell in a two step mechanism.

Table1. Potential parameters obtained from the response of GCE/PPI to $\mathrm{pH}$ in $0.1 \mathrm{M}$ phosphate buffer solution (Figure $4 \mathrm{~b}$ ) using both CV and SWV at $100 \mathrm{mV} / \mathrm{s}$.

\begin{tabular}{ccccc}
\hline \multirow{2}{*}{$\mathbf{p H}$} & $\mathbf{E p a}(\mathbf{m V})$ & $\mathbf{E p c}(\mathbf{m V})$ & $\mathbf{E}^{0^{\prime}}(\mathbf{m V})$ & $\Delta \mathbf{E}(\mathbf{m V})$ \\
\cline { 2 - 5 } & $\mathbf{C V}[\mathbf{S W V}]$ & $\mathbf{C V}$ & $\mathbf{C V}$ & $\mathbf{C V}$ \\
\hline 2.17 & $388[340]$ & 336 & 362 & 52 \\
4.13 & $320[284]$ & 270 & 295 & 50 \\
6.17 & $249[236]$ & 213 & 231 & 36 \\
7.04 & $223[216]$ & 201 & 212 & 22 \\
8.02 & $211[172]$ & 149 & 180 & 62 \\
10.16 & $-[155]$ & 186 & - & - \\
12.00 & - & - & - & - \\
\hline
\end{tabular}

\subsection{Electrochemical Impedance spectroscopy of GCE/PPI-AuNP}

Charge transfer resistance (in form of a semi circle) was not observed in the complex plane plot of the GCE/PPI-AuNP in PBS (Figure 5a). This observation is expected for a reversible system where the charge transfer is very facile (as seen in the high scan rates in Figure $4 a$ ) hence $\mathrm{R}_{\mathrm{ct}} \approx \mathrm{R}_{\mathrm{s}}$. Thus EIS also confirmed the reversible electrochemistry of PPI-AuNP as discussed with voltammetry. Total impedance (in PBS) of GCE/PPI-AuNP was remarkably lower than that of bare GCE, confirming the presence of a conducting layer. Figure $5 \mathrm{~b}$ shows the complex plane impedance behaviour of GCE/PPI-AuNP electrode system in $\mathrm{Fe}(\mathrm{CN})_{6}{ }^{3-4-}$ redox probe while Table 2 shows the equivalent circuit (Figure $5 \mathrm{~b}$ inset) parameters of GCE/PPI-AuNP at $200 \mathrm{mV}$. The $\mathrm{E}^{\circ \prime}$ and lowest $\mathrm{R}_{\mathrm{ct}}$ of $\mathrm{Fe}(\mathrm{CN})_{6}{ }^{3-14-}$ redox chemistry on GCE [33] and GCE/PPI-AuNP (not shown) occurred at ca $200 \mathrm{mV}$, hence the choice of $200 \mathrm{mV}$ as the bias potential in the EIS studies. The $\mathrm{Fe}(\mathrm{CN})_{6}{ }^{3-/ 4-}$ redox probe exhibited kinetic control and diffusion controlled electrochemistry at high and low frequency respectively at the PPI-AuNP interface. Complex phase element, CPE, was used in the model because the semi circle observed was depressed, the phase angle 
observed in the measurement was less than $90^{\circ}$ (not shown) and CPE is also appropriate to model the non ideal behaviour of the inhomogeneous electrode surface. Solution resistance, $R_{s}$, was used to model the electrolyte resistance at high frequency when the double layer capacitance is very small and the charge transfer kinetics is just at the onset. Charge transfer resistance, $\mathrm{R}_{\mathrm{ct}}$, corresponding to the diameter of the semicircle in Figure $5 \mathrm{~b}$ was used to model the resistance of the $\mathrm{Fe}(\mathrm{CN})_{6}{ }^{3-/ 4-}$ redox probe at the electrode surface. At a sufficiently low frequency, diffusion controlled process becomes limiting and this was modelled by Warburg impedance $\left(Z_{\mathrm{w}}\right)$.

Figure 5. (a) Nyquist plot of bare GCE and GCE/PPI-AuNP in PBS. (b) Nyquist plot of GCE, $\mathrm{GCE} / \mathrm{PPI}-\mathrm{AuNP}$ and GCE/PPI-AuNP/ssDNA in $5 \mathrm{mM} \mathrm{Fe}(\mathrm{CN})_{6}^{3-/ 4-}$ redox probe.
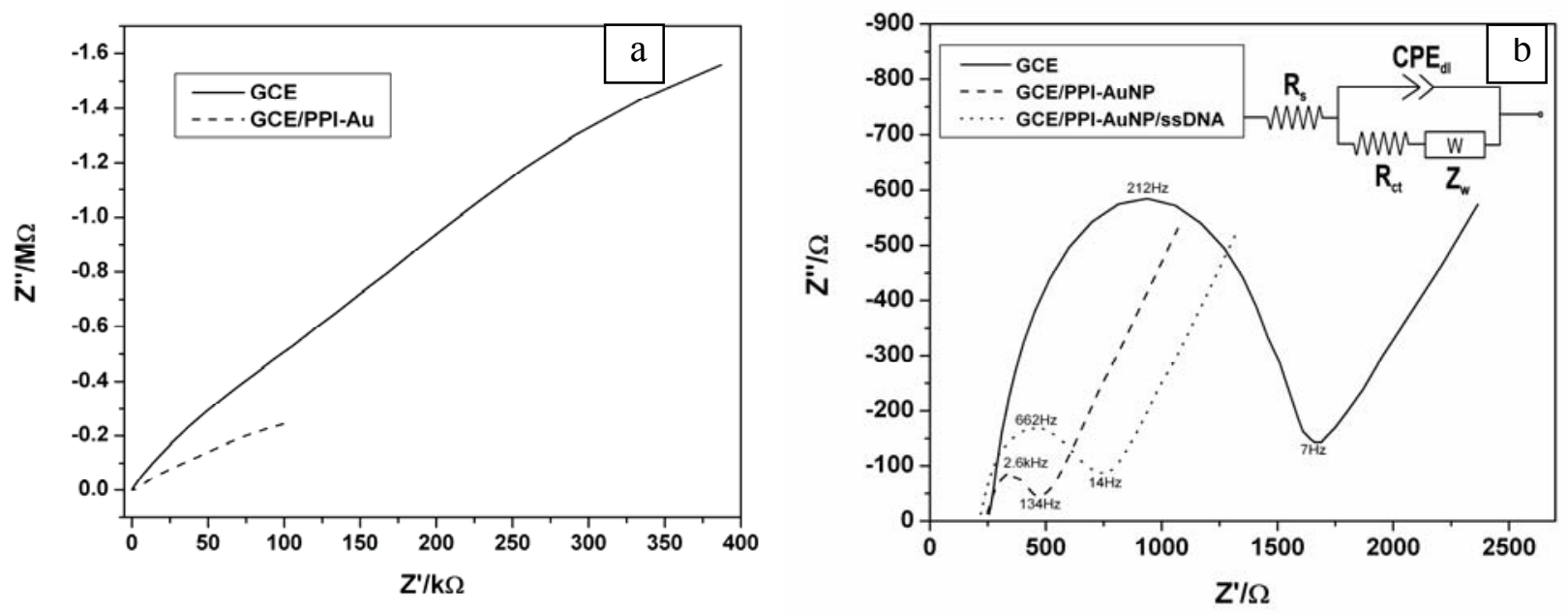

From Figure $5 \mathrm{~b}, \mathrm{R}_{\mathrm{ct}}$ for GCE/PPI-AuNP decreased by $81 \%$ compared to that of the bare GCE. The positively charged (cationic) platform ( $\mathrm{AuNP}$ is $\mathrm{Au}^{0}$ ) attracted the negatively charged $\mathrm{Fe}(\mathrm{CN})_{6}{ }^{3-4-}$ to its surface and facilitated the electron exchange for $\mathrm{Fe}(\mathrm{CN})_{6}{ }^{3 / 4}$. The result showed that the redox kinetics of $\mathrm{Fe}(\mathrm{CN})_{6}{ }^{3-/ 4-}$ was faster when GCE was modified with PPI-AuNP and this makes the platform more suitable for biosensor redox mediation in the presence of $\mathrm{Fe}(\mathrm{CN})_{6}{ }^{3-/ 4-}$ redox probe. The decreased $\mathrm{R}_{\mathrm{ct}}$ also suggests the improved conductivity. The PPI-AuNP can be said to have catalytic effect on the rate of the charge transfer kinetics or the faradaic process of the redox probe. This can be shown by calculating the time constant of the Faradaic process using the frequency $\left(\omega_{\max }\right)$ at the maximum imaginary impedance according to Eqns. 1a and $b$ [47]:

$$
\begin{aligned}
& \omega_{\max }=\frac{1}{R_{c t} C_{d l}} \\
& \tau=R_{c t} C_{d l}
\end{aligned}
$$

where $\mathrm{C}_{\mathrm{dl}}=$ double layer capacitance; $\tau=$ time constant; $\omega_{\max }=2 \pi f$

From Table 2, for the bare GCE, $\mathrm{R}_{\mathrm{ct}}=1348 \Omega, \omega_{\max }=2 \pi \times 212 \mathrm{~Hz}$ Therefore $\mathrm{C}_{\mathrm{dl}}=0.557 \mu \mathrm{F}$ and $\tau=$ $7.508 \times 10^{-4} \mathrm{~s} \mathrm{rad}^{-1}$. For GCE/PPI-AuNP, $\mathrm{R}_{\mathrm{ct}}=251.2 \Omega, \omega_{\max }=2 \pi \times 2.07 \mathrm{kHz}$. Therefore $\mathrm{C}_{\mathrm{dl}}=0.306 \mu \mathrm{F}$ 
and $\tau=7.687 \times 10^{-5} \mathrm{~s} \mathrm{rad}^{-1}$. The time constant values showed that the Faradaic process of the $\mathrm{Fe}(\mathrm{CN})_{6}{ }^{3 / 4-}$ probe is one order of magnitude faster on PPI-AuNP-modified GCE than on bare GCE, which confirms the catalytic effect of the PPI-AuNP film. Exchange current $i_{0}$, was used as a measure of the rate of electron transfer on the bare and modified GCE's. The $i_{0}$ of the electrode systems is given by

$$
i_{0}=\frac{R T}{n F R_{c t}}
$$

where R, F and $\mathrm{n}$ are gas constant, Faraday constant and number of electrons transferred, respectively. The $i_{0}$ values for the electron transfer reaction of $\mathrm{Fe}(\mathrm{CN})_{6}{ }^{3-/ 4-}$ on bare GCE and GCE/PPI-AuNP are 1.905 $\mathrm{x} 10^{-5} \mathrm{~A}$ and $1.022 \times 10^{-4} \mathrm{~A}$, respectively. Control experiments that were performed to check the behavior of the $\mathrm{Fe}(\mathrm{CN})_{6}^{3-/ 4-}$ probe on GCE/PPI (without Au-NP) gave $i_{0}$ values that were lower than what was obtained with GCE/PPI-AuNP. Thus, some possible reasons for the catalytic effect (increase in reaction rate) observed at the GCE/PPI-AuNP/ $\mathrm{Fe}(\mathrm{CN})_{6}{ }^{3-/ 4-}$ interface are: (i) nanostructured nature of the electrode surface, (ii) the enhanced surface area and conductivity due to AuNP, and (iii), an increase in $\mathrm{Fe}(\mathrm{CN})_{6}^{3-/ 4-}$ flux to the electrode surface due to the electrostatic attraction between the cationic platform and the anionic $\mathrm{Fe}(\mathrm{CN})_{6}^{3-/ 4-}$. A similar effect of improved electrochemical properties of $\mathrm{Fe}(\mathrm{CN})_{6}{ }^{3-/ 4-}$ using AuNP has been reported [52]. The ability of the PPI-AuNP platform to catalyze the $\mathrm{Fe}^{3+} / \mathrm{Fe}^{2+}$ redox reaction is a promising feature for redox mediation in enzymes which have Fe at the heme group. This catalytic effect was observed during the EIS measurements. It took $56 \mathrm{~s}$ to reach the $7 \mathrm{~Hz}$ (low frequency end of the charge transfer resistant) for GCE, whereas it took $29 \mathrm{~s}$ to reach $134 \mathrm{~Hz}$ frequency for GCE/PPI-AuNP.

Table 2. The EIS parameters obtained from the circuit fitting of plots in Figure $5 \mathrm{~b}$.

\begin{tabular}{lllll}
\hline Circuit element & $\mathbf{R}_{\mathbf{s}}(\boldsymbol{\Omega})$ & $\mathbf{R}_{\mathbf{c t}}(\boldsymbol{\Omega})$ & $\mathbf{C P E}(\mathbf{n F})$ & $\mathbf{Z}_{\mathbf{w}}$ \\
\hline GCE & 258 & 1348 & 463 & 699 \\
GCE/PPI-AuNP & 236 & 251 & 434 & 617 \\
GCE/PPI-AuNP/ssDNA & 212 & 528 & 468 & 604 \\
Average Error & 6.88 & 2.97 & 8.31 & 2.47 \\
\hline
\end{tabular}

\subsection{The voltammetric responses of the biosensor}

Apart from AuNP enhancing the $\mathrm{R}_{\mathrm{ct}}$ of $\mathrm{Fe}(\mathrm{CN})_{6}{ }^{3-4-}$ [52], AuNP was also incorporated into the composite for the purpose of connecting the thiolated probe ssDNA to the GCE surface via a Au-S linkage $[37,41]$. The probe immobilization effectiveness would also be improved by an electrostatic attraction between the cationic platform and the anionic DNA probe. Figure 6a presents the cyclic voltammetric responses of the bare GCE, GCE/PPI-AuNP (the platform), GCE/PPI-AuNP/ssDNA (the biosensor) and GCE/PPI-AuNP/dsDNA (the hybridized biosensor). The biosensor stability monitored over a period of 30 days shown in Figure 6b, indicates effective adsorption of the probe DNA on the PPI-AuNP platform. As can be seen in Figure 6a, there was a $36 \%$ attenuation of the anodic peak current $\left(\mathrm{I}_{\mathrm{pa}}\right)$ of GCE/PPI-AuNP after the immobilization of the target ssDNA. However, the $\mathrm{I}_{\mathrm{pa}}$ increased by $20 \%$ after exposing the 
resulting DNA biosensor to $0.05 \mathrm{nM}$ target ssDNA (hybridization). This phenomenon may be attributed to the electrical or charge transportation properties of DNA. Various researchers [53-57], have shown that DNA charge-transfer characteristics can be explained on the basis of the two most fundamental processes for electron transfer in extended electronic systems, which are coherent tunnelling and diffusive thermal hopping. Furthermore, DNA's ability to undergo electron transfer and its conductivity are due to its ability to adopt different structures along the molecule as well as the polyelectrolyte character of the double helix, which may lead to the flow of positively charged counter ions along the negatively charged phosphate backbone, with electrons and holes appearing to shuttle along a single DNA molecule over a distance of a few nanometres. While most of these views are based on the bases (i.e. guanine, cytosine, adenosine and thymine) in DNA, electron delocalization in the conducting band through the phosphate backbone has also been proposed [58]. Based on these theories of DNA behaviour, the electrochemical responses of the GCE/PPI-AuNP after probe ssDNA immobilization and hybridization with target ssDNA can be attributed to the possibility of charge transfer between the cationic PPI and DNA base stacks and/or anionic backbone. Though DNA is not electroactive at $+230 \mathrm{mV}$ unlike the PPI (Figure 3c), its 2-deoxyriboso-5-phosphate backbone, provides with PPI a supramolecular setting in which protons can be delocalized over a wider space and their contribution could be under potential control. Earlier studies [55] have shown that PPI can be an efficient hydrogen donor. It can therefore be speculated that DNA's conductivity allowed a certain degree of protonation of PPI (Scheme 1).

Scheme 1. Proposed charge transfer scheme between the PBS electrolyte, DNA and PPIAuNP.

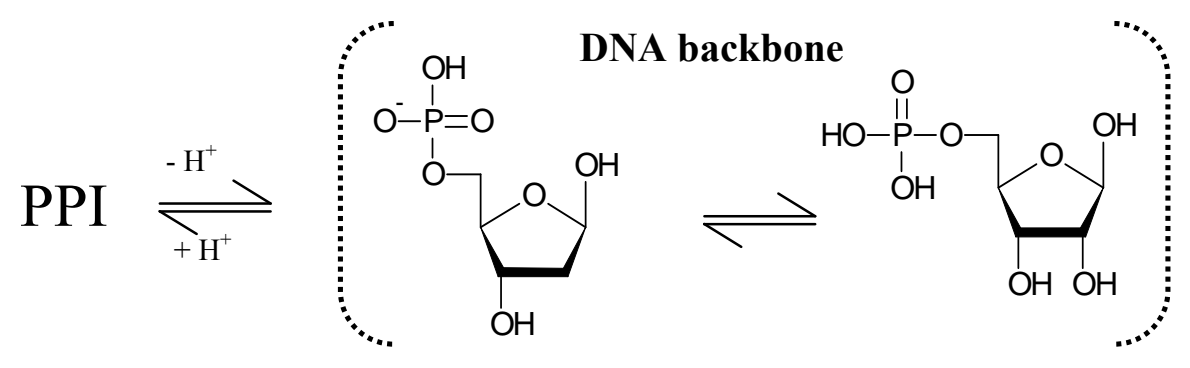

Also the fact that electron or charge is able to tunnel through the DNA base stack can also lead to a delocalized electron flow between the DNA and PPI molecules. The increase in the number of the more conducting guanine-cytosine (G-C) base pairs as a result of the formation of dsDNA is responsible for the increased current when the biosensor was hybridized. 
Figure 6. (a) $\mathrm{CV}$ of GCE/PPI-AuNP/ssDNA (developed with $2 \mu \mathrm{M}$ thiolated ssDNA) and GCE/PPI-AuNP/dsDNA (i.e. response to $0.5 \mathrm{nM}$ DNA target ssDNA) in PBS at $20 \mathrm{mV} / \mathrm{s}$. (b) Differential pulse voltammograms of GCE/PPI-AuNP/ssDNA biosensor in PBS when stored for 30 days.
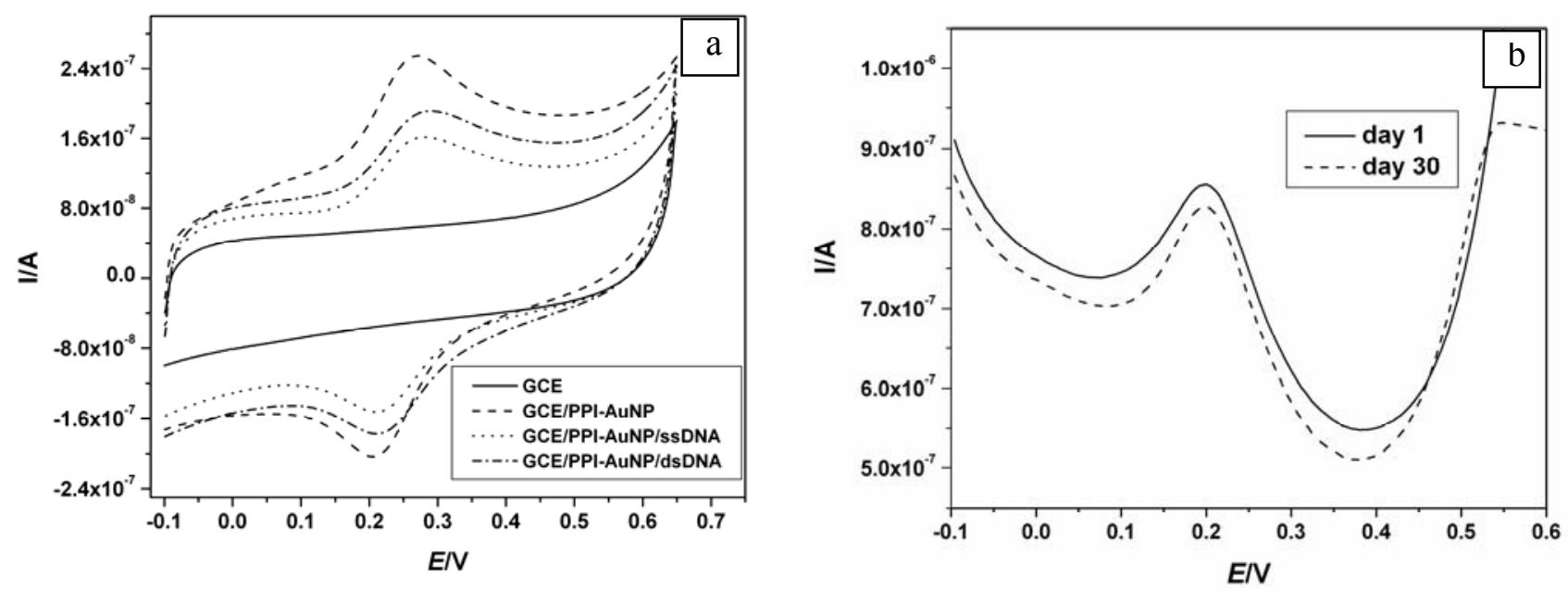

\subsection{Impedimetric responses of the biosensors}

During the analysis of the spectra in Figure 5b, it was observed that $\mathrm{R}_{\mathrm{ct}}$ increased by $276.4 \Omega$ (Table 2 ) when the probe DNA was immobilised. The reason for this is that the negatively charged phosphate backbone of the single strand DNA attached to the platform repels the anionic $\mathrm{Fe}(\mathrm{CN})_{6}{ }^{3-/ 4-}$ redox probe. As shown in Figure 7a, after the pairing up (hybridisation) with target DNA, the anionic density of the resultant GCE/PPI-AuNP/dsDNA further increased the barrier for interfacial electron transfer because of the double strands formed, which further repelled the negatively charged $\mathrm{Fe}(\mathrm{CN})_{6}{ }^{3-/ 4-}$ redox probe and thus increased the $\mathrm{R}_{\mathrm{ct}}$ [60]. The Kramers Kronig transform (Eqn. 3) was used to validate the impedimetric responses shown in Figure 7. This integral equation allows the imaginary impedance, $Z^{\prime \prime}$, to be calculated from the real impedance, $Z^{\prime}$, data. The experimental and calculated imaginary impedance show very good correlation as seen in Figure $7 \mathrm{~b}$.

$$
Z^{\prime \prime}(\omega)=-\frac{2 \omega}{\pi} \int_{0}^{\infty} \frac{Z^{\prime}(x)-Z^{\prime}(\omega)}{x^{2}-\omega^{2}} d x
$$

The impedance spectra in Figure $7 \mathrm{a}$ were fitted to the equivalent circuit in Figure $5 \mathrm{~b}$ (inset) where the parallel $\mathrm{R}_{\mathrm{ct}}$ and CPE were used to model the combination of the three layers, namely, the platform, probe DNA and target DNA. As explained earlier, the absence of a second semicircle is due to the fast redox of the platform chemistry. Hence, the $\mathrm{R}_{\mathrm{ct}}$ of $\mathrm{Fe}(\mathrm{CN})_{6}{ }^{3-/ 4-}$ reports the DNA/ $\mathrm{Fe}(\mathrm{CN})_{6}{ }^{3-/ 4-}$ interfacial kinetics. Table 3 shows the values obtained from the circuit fitting. Fitting errors were less than $1 \%$ for $\mathrm{R}_{\mathrm{ct}}$, which was chosen as the analytical parameter and less than $10 \%$ (not shown) for other circuit elements. Figure $7 \mathrm{a}$ inset shows the calibration plot of the DNA biosensor. A correlation coefficient, $\mathrm{R}^{2}=0.992$ and a sensitivity of $174 \Omega / \log M$ were obtained. 
Figure 7. (a) Nyquist plots of the biosensor responses to $0.01 \mathrm{nM}$ to $5 \mathrm{nM}$ of target DNA in the presence of $\mathrm{Fe}(\mathrm{CN})_{6}^{3-/ 4-}$ redox probe; (b) Kramer-Kronig $(\mathrm{KK})$ plot for data validation. $Z^{\prime}$ $=$ experimental real impedance; $\mathrm{LKK}^{\prime \prime}=$ imaginary impedance calculated with the KramerKronig equation; and $Z^{\prime \prime}=$ the experimental imaginary impedance.
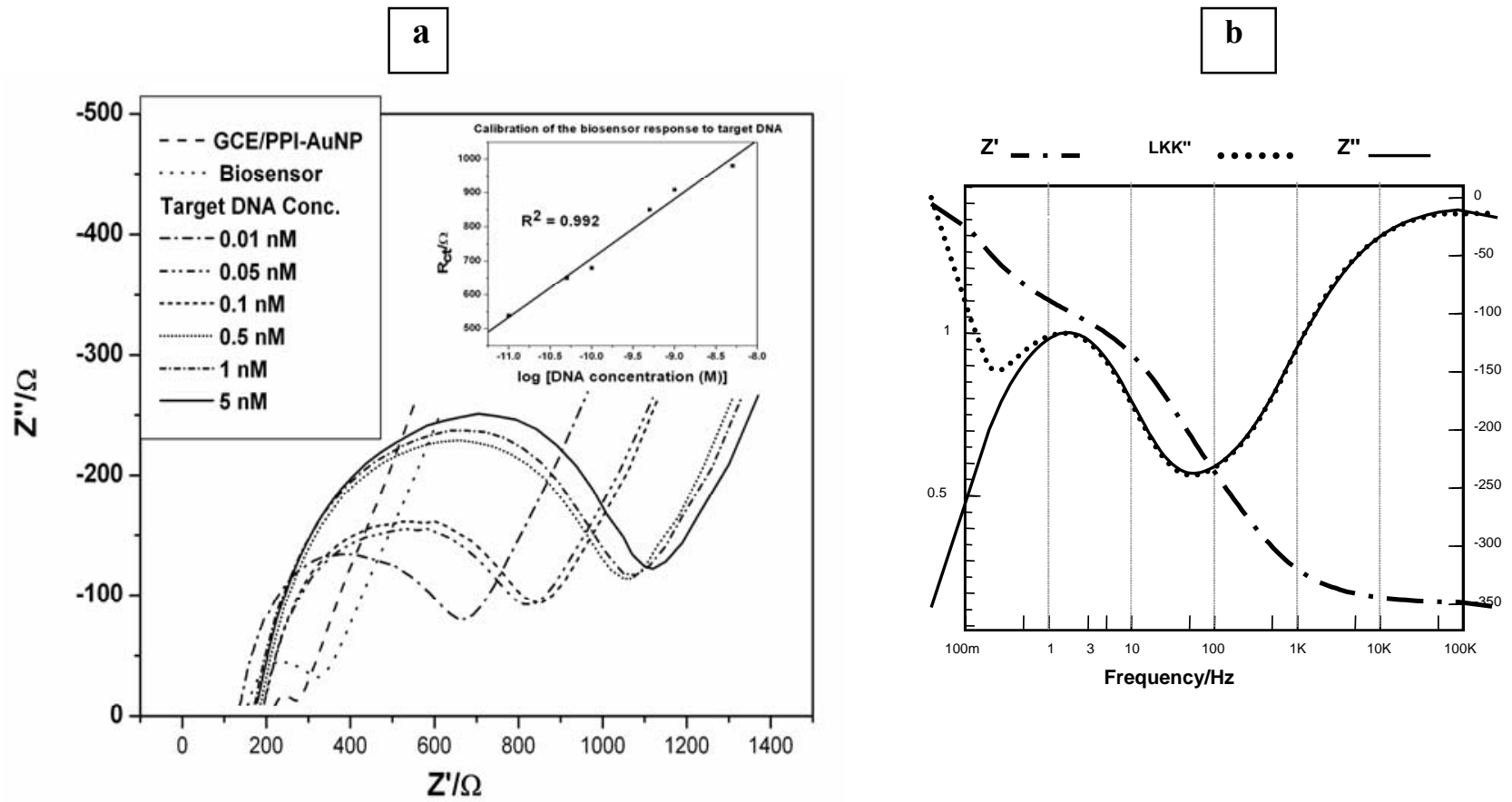

Table 3. EIS parameters of GCE/PPI-AuNP/dsDNA obtained from Figure 7a.

\begin{tabular}{lllllll}
\hline Target DNA conc. $(\mathbf{n M})$ & $\mathbf{0 . 0 1}$ & $\mathbf{0 . 0 5}$ & $\mathbf{0 . 1}$ & $\mathbf{0 . 5}$ & $\mathbf{1}$ & $\mathbf{5}$ \\
$\log ($ Target DNA conc. $(\mathbf{n M}))$ & $\mathbf{- 1 1}$ & $\mathbf{- 1 0 . 3}$ & $\mathbf{- 1 0}$ & $\mathbf{- 9 . 3}$ & $\mathbf{- 9}$ & $\mathbf{- 8 . 3}$ \\
\hline $\mathbf{R}_{\mathbf{c t}}(\boldsymbol{\Omega})$ & 538.3 & 651.2 & 680.5 & 850.4 & 908.8 & 981 \\
Error $\left(\mathbf{R}_{\mathrm{ct}}\right)$ & 0.43 & 1.24 & 0.93 & 0.6 & 0.36 & 0.53 \\
$\mathbf{R}_{\mathbf{s}}(\boldsymbol{\Omega})$ & 127.4 & 183 & 182.9 & 176.4 & 161.8 & 167.4 \\
$\mathbf{C P E}(\mathbf{n F})$ & 852 & 871.3 & 850.5 & 802.7 & 830 & 812.8 \\
$\mathbf{Z}_{\mathbf{w}}$ & 301.3 & 286.2 & 286.7 & 288.5 & 282.9 & 285.1 \\
\hline
\end{tabular}

\section{Experimental}

\subsection{Materials}

Ultra pure water with resistivity $18.2 \mathrm{M} \Omega$ was prepared using a Millipore Synergy water purification system. All reagents were of analytical grade. Oligonucleotides (referred to as DNA) of 20 bases were supplied by Inqaba Biotechnical (Pty) Ltd, Cape Town, South Africa. The probe and complementary DNA's were SH-5'-AAGCGGAGGATTGACGACTA-3' and 5'-TAGTCGTCAATCCTCCGCTT-3', 
respectively. Generation 4 (G4) poly(propyleneimine) dendrimer was purchased from SyMO-Chem, Eindhoven, Netherlands. $\mathrm{HAuCl}_{4}$ was obtained from Sigma Aldrich and used as received.

\subsection{Solutions}

Phosphate buffer saline solution (PBS) of $\mathrm{pH} 7.2$ was prepared with $10 \mathrm{mM}$ of $\mathrm{Na}_{2} \mathrm{HPO}_{4}, \mathrm{KH}_{2} \mathrm{PO}_{4}$ and $0.3 \mathrm{mM} \mathrm{KCl}$, while the non-saline was without $\mathrm{KCl}$ and is simply referred to as phosphate buffer solution. Five $\mathrm{mM}(1: 1)$ solution of $\mathrm{K}_{3} \mathrm{Fe}(\mathrm{CN})_{6}$ and $\mathrm{K}_{4} \mathrm{Fe}(\mathrm{CN})_{6}\left(\left[\mathrm{Fe}(\mathrm{CN})_{6}\right]^{3-4-}\right)$ was prepared in $10 \mathrm{mM}$ phosphate buffer solution $(100 \mathrm{~mL})$ at $\mathrm{pH}$ 7.2. For $\mathrm{pH}$ studies, $0.1 \mathrm{M}$ phosphate buffer solutions of $\mathrm{pHs}$ ranging from 2 to 12 (corrected with $\mathrm{HCl}$ and $\mathrm{NaOH}$ ) were prepared. $100 \mu \mathrm{M}$ of DNA stock was prepared in tris-EDTA buffer ( $\mathrm{pH}$ 8.00) and stored at $-20{ }^{\circ} \mathrm{C}$. Working DNA solutions were prepared by diluting the stock solution to the desired concentrations in phosphate buffer solution, stored at $4{ }^{\circ} \mathrm{C}$ and not used when older than 4 weeks. Solutions of $6 \mathrm{mM} \mathrm{G} 4$ PPI (Molecular mass $=3514 \mathrm{~g} / \mathrm{mol}$ ) and $5 \mathrm{mM} \mathrm{HAuCl}_{4}$ were prepared in water.

\subsection{Equipment and apparatus}

A three electrode system was used to perform all electrochemical experiments. A glassy carbon electrode (GCE) with $0.3 \mathrm{~cm}$ diameter was used as the working electrode, a platinum wire served as the counter electrode, and $\mathrm{Ag} / \mathrm{AgCl}\left(3 \mathrm{M} \mathrm{Cl}^{-}\right)$as the reference electrode. All voltammetric experiments were performed on an Epsilon (BASi) electrochemical workstation (LaFayette) with oxidative scan direction except stated otherwise. Square wave voltammetry (SWV) measurements were performed by applying an amplitude of $25 \mathrm{mV}$ and frequency of $15 \mathrm{~Hz}$. Differential pulse voltammetry (DPV) measurements were recorded using pulse amplitude of $50 \mathrm{mV}$, sample width of $10 \mathrm{msec}$, pulse period of $200 \mathrm{msec}$. EIS measurements were recorded with a Zahner IM6ex (Germany), at a perturbation amplitude of $10 \mathrm{mV}$ within the frequency range of $100 \mathrm{kHz}$ to $100 \mathrm{mHz}$. All solutions for electrochemical measurements were de-aerated by bubbling argon through it for 10 minutes. FE-SEM images were captured using a field emission electron microscope (JEOL- JSM 7500F) fitted with a EDAX CDU Leap Detector.

\subsection{Electro-preparation of platforms and development of the DNA biosensor}

\subsubsection{Preparation of GCE/PPI, GCE/AuNP and GCE/PPI-AuNP modified electrodes}

For all electro-deposition processes, the GCE was mechanically polished with 0.3 and 0.05 micron alumina powder, rinsed with water and then ultrasonicated in water for 4 minutes. The cleanliness of the surface was verified in PBS with potential range of $-100 \mathrm{mV}$ to $+650 \mathrm{mV}$ where no peak was expected. GCE/Au-NP was prepared by electrodepositing AuNP on clean GCE surface by cycling the electrode potential from $-350 \mathrm{mV}$ to $+1000 \mathrm{mV}$ for 10 cycles at $50 \mathrm{mV} / \mathrm{s}$ using $2.5 \mathrm{mM}$ aqueous $\mathrm{HAuCl}_{4}$ as the electrolyte. GCE/PPI was prepared as described for GCE/AuNP except that $3 \mathrm{mM}$ PPI aqueous solution as 
electrolyte instead of $\mathrm{HAuCl}_{4}$. The preparation of GCE/PPI-AuNP electrode system involved the simultaneous cyclic voltammetric deposition of PPI and AuNP on a clean GCE from an argon-degassed electrolyte consisting of $6 \mathrm{mM}$ PPI and $5 \mathrm{mM} \mathrm{HAuCl}_{4}$ in a 1:1 v/v ratio. The GCE/AuNP, GCE/PPI and GCE/PPI-AuNP modified electrodes were rinsed with water and characterized by CV, SWV and EIS; and stored at $4{ }^{\circ} \mathrm{C}$ when not in use. However, Screen printed carbon electrode (SPCE) was used as substrate (under the same electro-deposition conditions) for FE-SEM measurements.

3.4.2 Immobilization of probe DNA (GCE/PPI-AuNP/ssDNA) and hybridization with target DNA (GCE/PPI-AuNP/dsDNA)

The GCE/PPI-AuNP/ssDNA nanobiosensor was prepared by dropping a $20 \mu \mathrm{L}$ solution of $2 \mu \mathrm{M}$ thiolated single strand probe DNA (or probe ssDNA) on the surface of a previously argon-dried GCE/PPIAuNP, and leaving it to immobilize for $3 \mathrm{~h}$ at $25{ }^{\circ} \mathrm{C}$ and then successively rinsing with water and phosphate buffer solution to remove any unbound probe ssDNA. The biosensor was stored at $4{ }^{\circ} \mathrm{C}$ when not in use. The biosensor was characterized by voltammetry and EIS in PBS and $5 \mathrm{mM}(1: 1)$ ferro/ferricyanide solution $\mathrm{Fe}(\mathrm{CN})_{6}{ }^{3 / 4-}$, respectively.

The bio-recognition experiments, was carried out in PBS $(1 \mathrm{~mL})$ containing six different concentrations of complementary ssDNA (target ssDNA) ranging from 0.01 to $5 \mathrm{nM}$. For each hybridization step (each target DNA concentration), the nanobiosensor (GCE/PPI-AuNP/ssDNA) was immersed in the target ssDNA solution for $45 \mathrm{~min}$ at $38^{\circ} \mathrm{C}$. The hybridized biosensor (i.e. GCE/PPI-AuNP/dsDNA) was washed thoroughly with water and phosphate buffer solution to remove unbound target ssDNA before making measurements. The impedimetric responses of the biosensor to the target ssDNA were measured in PBS using $\mathrm{Fe}(\mathrm{CN})_{6}^{3-/ 4-}$ as the redox probe. However a single concentration of $0.05 \mathrm{nM}$ complementary DNA was used to investigate the voltammetric response.

\section{Conclusions}

A new method of modifying GCE with poly(propyleneimine) dendrimer and a gold nanoparticle nanocomposite and exploiting their properties for immobilization of ssDNA was developed. The GCE/PPI-AuNP nanocomposite platform exhibited reversible electrochemistry, good conductivity, $\mathrm{pH}$ sensitivity and excellent catalytic properties toward $\mathrm{Fe}(\mathrm{CN})_{6}{ }^{3-/ 4-}$ redox probe. This DNA biosensor was highly sensitive; to the extent that it was able to amperometrically detect target DNA concentrations as low as $0.05 \mathrm{nM}$ in phosphate buffer solution. Using impedimetric detection techniques, the biosensor had a dynamic linearity of $10^{-12}$ to $10^{-9} \mathrm{M}$ for target DNA $\left(\mathrm{R}^{2}=0.992\right)$, which was an order of magnitude improvement in the limit of detection compared to previous studies that reported a linearity of $10^{-11}$ to $10^{-7}$ M [32,61]. This study also showed that owing to the favourable biomolecular immobilization properties of dendrimers and the possibility of modifying their inner core, the PPI-modified GCE can also be applied in enzyme and antibody biosensors. 


\section{Acknowledgements}

The research was funded by the National Research Foundation (NRF) of South Africa Focus Area Grant. We wish to thank Miss Munkombwe Muchindu of SensorLab for her assistance with the FE-SEM analysis.

\section{References and Notes}

1. Iwuoha, E.I.; Smyth, M.R. Reactivities of organic phase biosensors: 6. Square-wave and differential pulse studies of genetically engineered cytochrome P450 cam (CYP101) bioelectrodes in selected solvents. Biosens. Bioelectron. 2003, 18, 237-244.

2. Iwuoha, E.; Ngece, R.; Klink, M.; Baker, P. Amperometric responses of CYP2D6 drug metabolism nanobiosensor for sertraline: a selective serotonin reuptake inhibitor. IET Nanobiotech. 2007, 1, 62 67.

3. Zejli, H.; Cisneros, J.L.H.H.d.; Rodriguez, I.N.; Liu, B.; Temsamani, K.R.; Marty, J.L. Phenol biosensor based on Sonogel-Carbon transducer with tyrosinase alumina sol-gel immobilization. Anal. Chim. Acta 2008, 612, 198-203.

4. Somerset, V.S.; Klink, M.J.; Baker, P.G.L.; Iwuoha, E.I. Acetylcholinesterase-polyaniline biosensor investigation of organophosphate pesticides in selected organic solvents. J. Environ. Sci. Health B 2007, 42, 297-304.

5. Gore, M.R.; Szalai, V.A.; Ropp, P.; Yang, I.V.; Silverman, J.S.; Thorp, H.H. Detection of Attomole Quantitites of DNA Targets on Gold Microelectrodes by Electrocatalytic Nucleobase Oxidation. Anal. Chem. 2003, 75, 6586-6592.

6. Owino, J.H.O.; Ignaszak, A.; Ahmed, A.A.; Baker, P.G.L.; Alemu, H.; Ngila, J.C.; Iwuoha, E.I. Modelling of the impedimetric responses of an aflatoxin B1 immunosensor prepared on an electrosynthetic polyaniline platform. Anal. Bioanal. Chem. 2007, 388, 1069.

7. Drummond, T.G.; Hill, M.G.; Barton, J.K. Electrochemical DNA sensors. Nat. Biotechnol. 2003, 21, 1192-1199.

8. Lucarelli, F.; Tombelli, S.; Minunni, M.; Marrazza, G.; Mascini, M. Electrochemical and piezoelectric DNA biosensors for hybridisation detection. Anal. Chim. Acta 2008, 609, 139-159.

9. Bontidean, I.; Mortari, A.; Leth, S.; Brown, N.L.; Karlson, U.; Larsen, M.M.; Vangronsveld, J.; Corbisier, P.; Csöregi, E. Biosensors for detection of mercury in contaminated soils. Environ. Pollut. 2004, 131, 255-262.

10. Nakamura, H.; Karube, I. Current research activity in biosensors. Anal. Bioanal. Chem. 2003, 377, 446-468.

11. Mascini, M. Affinity electrochemical biosensors for pollution control. Pure Appl. Chem. 2001, 73, 23-30.

12. Luckarift, H.R.; Greenwald, R.; Bergin, M.H.; Spain, J.C.; Johnson, G.R. Biosensor system for continuous monitoring of organophosphate aerosols. Biosens. Bioelectron. 2007, 23, 400-406. 
13. Bagni, G.; Osella, D.; Sturchio, E.; Mascini, M. Deoxyribonucleic acid (DNA) biosensors for environmental risk assessment and drug studies. Analytica Chimica Acta 2006, 573-574, 81-89.

14. Berganza, J.; Olabarria, G.; Garcia, R.; Verdoy, D.; Rebollo, A.; Arana, S. DNA microdevice for electrochemical detection of Escherichia coli 0157:H7 molecular markers. Biosens. Bioelectron. 2007, 22, 2132-2137.

15. LaGier, M.J.; Fell, J.W.; Goodwin, K.D. Electrochemical detection of harmful algae and other microbial contaminants in coastal waters using hand-held biosensors. Marine Pollut. Bull. 2007, 54, 757-770.

16. Patel, P.D. (Bio)sensors for measurement of analytes implicated in food safety: a review. Trends Anal. Chem. 2002, 21, 96-115.

17. Gáspár, C.S.; Leth, S.; Niculescu, M.; Mortari, A.; Bontidean, I.; Soukharev, V.; Dorneanu, S.A.; Ryabov, A.D.; Csöregi, E. Biosensors for life quality: Design, development and applications. Sens. Actuat. B-Chem. 2004, 102, 179-194.

18. Smith, R.G.; D'Souza, N.; Nicklin, S. A review of biosensors and biologically-inspired systems for explosives detection. Analyst 2008, in press.

19. Viveros, L.; Paliwal, S.; McCrae, D.; Wild, J.; Simonian, A. A fluorescence-based biosensor for the detection of organophosphate pesticides and chemical warfare agents. Sens. Actuat. B-Chem. 2006, 115, 150-157.

20. Brett, A.M.O.; Paquim, A.M.C.; Diculescu, V.; Oretskaya, T.S. Synthetic oligonucleotides: AFM characterisation and electroanalytical studies. Bioelectrochemistry 2005, 67, 181-190.

21. Cloarec, J.P.; Chevolot, Y.; Laurenceau, E.; Phaner-Goutorbe, M.; Souteyrand, E. A multidisciplinary approach for molecular diagnostics based on biosensors and microarrays. ITBMRBM 2008, 29, 105-127.

22. Sassolas, A.; Bouvier, B.D.L.; Blum, L.J. DNA Biosensors and Microarrays. Chem. Rev. 2008, 108, 109-139.

23. Lo, P.-H.; Kumar, S.A.; Chen, S.-M. Amperometric determination of $\mathrm{H}_{2} \mathrm{O}_{2}$ at nano$\mathrm{TiO}_{2} / \mathrm{DNA} /$ thionin nanocomposite modified electrode. Coll. Surf. B: Biointerf. 2008, 66, 266-273.

24. Zhang, W.; Yang, T.; Huang, D.; Jiao, K.; Li, G. Synergistic effects of nano-ZnO/multi-walled carbon nanotubes/chitosan nanocomposite membrane for the sensitive detection of sequence-specific of PAT gene and PCR amplification of NOS gene. J. Membr. Sci. 2008, 325, 245-251.

25. Ghanbari, K.; Bathaie, S.Z.; Mousavi, M.F. Electrochemically fabricated polypyrrole nanofibermodified electrode as a new electrochemical DNA biosensor. Biosens. Bioelectron. 2008, 23, 18251831.

26. Fréchet, J.M. Functional polymers and dendrimers: reactivity, molecular architecture, and interfacial energy. Science 1994, 263, 1710-1715.

27. Svenson, S.; Tomalia, D.A. Dendrimers in biomedical applications - reflections on the field. Adv. Drug Deliv. Rev. 2005, 57, 2106-2129.

28. Boas, U.; Heegaard, P.M.H. Dendrimers in drug research. Chem. Soc. Rev. 2004, 33, 43-63. 
29. Dufes, C.; Uchegbu, I.F.; Schatzlein, A.G. Dendrimers in gene delivery. Adv. Drug Deliv. Rev. 2005, 57, 2177-2202.

30. Astruc, D.; Chardac, F. Dendritic Catalysts and Dendrimers in Catalysis. Chem. Rev. 2001, 101, 2991-3023.

31. Malgas, R.; Mapolie, S.F.; Ojwach, S.O.; Smith, G.S.; Darkwa, J. The application of novel dendritic nickel catalysts in the oligomerization of ethylene. Catal. Commun. 2008, 9, 1612-1617.

32. Agashe, H.B.; Babbar, A.K.; Jain, S.; Sharma, R.K.; Mishra, A.K.; Asthana, A.; Garg, M.; Dutta, T.; Jain, N.K. Investigations on biodistribution of technetium-99m-labeled carbohydrate-coated poly(propylene imine) dendrimers. Nanomedicine NBM 2007, 3, 120-127.

33. Arotiba, O.A.; Ignaszak, A.; Malgas, R.; Al-Ahmed, A.; Baker, P.G.L.; Mapolie, S.F.; Iwuoha, E.I. An electrochemical DNA biosensor developed on novel multinuclear nickel (II) salicylaldimine metallodendrimer platform. Electrochim. Acta 2007, 53, 1689-1696.

34. McCarthy, T.D.; Karellas, P.; Henderson, S.A.; Giannis, M.; O'Keefe, D.F.; Heery, G.; Paull, J.R.A.; Matthews, B.R.; Holan, G. Dendrimers as Drugs: Discovery and Preclinical and Clinical Development of Dendrimer-Based Microbicides for HIV and STI Prevention Molec. Pharmacol. 2005, 2, 312-318.

35. Newkome, G.R.; Shreiner, C.D. Poly (amidoamine), polypropylenimine, and related dendrimers and dendrons possessing different $1 \rightarrow 2$ branching motifs: An overview of the divergent procedures. Polymer 2008, 49, 1-173.

36. Willner, I.; Baron, R.; Willner, B. Integrated nanoparticle-biomolecule systems for biosensing and bioelectronics. Biosens. Bioelectron. 2007, 22, 1841-1852.

37. Daniels, M.C.; Astruc, D. Gold Nanoparticles: Assembly, Supramolecular Chemistry, QuantumSize-Related Properties, and Applications toward Biology, Catalysis, and Nanotechnology Chem. Rev. 2004, 104, 293-346.

38. Liu, S.; Leech, D.; Ju, H. Application of Colloidal Gold in Protein Immobilization, Electron Transfer, and Biosensing. Anal. Lett. 2003, 36, 1-19.

39. Shulga, O.; Kirchhoff, J.R. An acetylcholinesterase enzyme electrode stabilized by an electrodeposited gold nanoparticle layer. Electrochem. Commun. 2007, 9, 935-940.

40. Katz, E.; Willner, I. Probing Biomolecular Interactions at Conductive and Semiconductive Surfaces by Impedance Spectroscopy: Routes to Impedimetric Immunosensors, DNA-Sensors, and Enzyme Biosensors. Electroanalysis 2003, 15, 913.

41. Lucarelli, F.; Marrazza, G.; Mascini, M. Enzyme-based impedimetric detection of PCR products using oligonucleotide-modified screen-printed gold electrodes Biosens. Bioelectron. 2005, 20, 20012009.

42. Pingarrón, J.M.; Yáñez-Sedeño, P.; González-Cortés, A. Gold nanoparticle-based electrochemical biosensors. Electrochim. Acta 2008, 53, 5848-5866.

43. Krasteva, N.; Guse, B.; Besnard, I.; Yasuda, A.; Vossmeyer, T. Gold nanoparticle/PPI-dendrimer based chemiresistors: Vapor-sensing properties as a function of the dendrimer size. Sens. Actuat. BChem. 2003, 92, 137-143. 
44. Barbier, B.; Pinson, J.; Desarmot, G.; Sanchez, M. Electrochemical bonding of amines to carbon fiber surfaces toward improved carbon-epoxy composites J. Electrochem. Soc. 1990, 137, 17571764.

45. Deinhammer, R.S.; Ho, M.; Anderegg, J.W.; Porter, M.D. Electrochemical Oxidation of AmineContaining Compounds: A Route to the Surface Modification of Glassy Carbon Electrodes. Langmuir 1994, 10, 1306-1313.

46. Downard, A.J. Electrochemically assisted covalent modification of carbon electrodes. Electroanalysis 2000, 12, 1085-1096

47. Krause, S. Impedance Methods. In Encyclopedia of Electrochemistry; Bard, A.J.; Stratman, M.; Unwin, P.R., Eds.; WILEY-VCH Verlag GmgH \& Co. KGaA: Weinheim, 2003; Vol. 3, Ch. 2.

48. Kabanov, V.A.; Zezin, A.B.; Rogacheva, V.B.; Gulyaeva, Z.G.; Zansochova, M.F.; Joosten, J.G.H.; Brackman, J. Polyelectrolyte Behavior of Astramol Poly(propyleneimine) Dendrimers. Macromolecules 1998, 31, 5142-5144.

49. van-Duijvenbode, R.C.; Borkovec, M.; Koper, G.J.M. Acid-base properties of poly(propylene imine)dendrimers. Polymer 1998, 39, 2657-2664.

50. Ferreira, V.; Tenreiro, A.; Abrantes, L.M. Electrochemical, microgravimetric and AFM studies of polythionine films Application as new support for the immobilisation of nucleotides. Sens. Actuat. B- Chem. 2006, 119, 632-641.

51. Koper, G.J.M.; vanGenderen, M.H.P.; Elissen-Roman, C.; Baars, M.W.P.L.; Meijer, E.W.; Borkovec, M. Protonation Mechanism of Poly(propylene imine) Dendrimers and Some Associated Oligo Amines J. Am. Chem. Soc. 1997, 119, 6512-6521.

52. Cheng, W.; Dong, S.; Wang, E. Gold Nanoparticles as Fine Tuners of Electrochemical Properties of the Electrode/Solution Interface. Langmuir 2002, 18, 9947-9952.

53. Kelly, S.O.; Barton, J.K. Electron transfer between bases in double helical DNA. Science 1999, 283, 375-381.

54. Giese, B.; Amaudrut, J.; Kohler, A.K.; Spormann, M.; Wessely, S. Direct observation of hole transfer through DNA by hopping between adenine bases and by tunneling. Nature 2001, 412, 318320.

55. Flink, H.W.; Schoenenberger, C. Electrical conduction through DNA molecules. Nature 1999, 398, 407-410.

56. Berlin, Y.A.; Burin, A.L.; Ratner, M.A. Charge Hopping in DNA. J. Am. Chem. Soc. 2001, 123, 260-268.

57. Cohen, H.; Nogues, C.; Naaman, R.; Porath, D. Direct measurement of electrical transport through single DNA molecules of complex sequence. Proc. Natl. Acad. Sci. USA 2005, 102, 11589-11593.

58. Ikeura-Sekiguchi, H.; Sekiguchi, T. Attosecond Electron Delocalization in the Conduction Band through the Phosphate Backbone of Genomic DNA. Phys. Rev. Lett. 2007, 99, 228102.

59. Tasdelen, M.A.; Demirel, A.L.; Yagci, Y. Poly(propylene imine) dendrimers as hydrogen donor in Type II photoinitiated free radical polymerization. Eur. Polymer J. 2007, 43, 4423-4430. 
60. Liu, J.; Tian, S.; Nielsen, P.E.; Knoll, W. In situ hybridization of PNA/DNA studied label-free by electrochemical impedance spectroscopy. Chem. Commun. 2005, 2969 - 2971.

61. Gu, H.; Su, X.d.; Loh, K.P. Electrochemical Impedance Sensing of DNA Hybridization on Conducting Polymer Film-Modified Diamond. J. Phys. Chem. B 2005, 109, 13611-13618.

(C) 2008 by the authors; licensee Molecular Diversity Preservation International, Basel, Switzerland. This article is an open-access article distributed under the terms and conditions of the Creative Commons Attribution license (http://creativecommons.org/licenses/by/3.0/). 